\title{
Acute dermatomyositis associated with a staphylococcal infection
}

\author{
A. M. Heagerty \\ M.B., M.R.C.P.
}

N. P. BYrom

M.B., M.R.C.P.
J. B. CoOKSON M.D., M.R.C.P.

University of Leicester, Department of Medicine, Clinical Sciences Building, PO Box 65, Leicester Royal ${ }^{\infty}$ Infirmary, Leicester LE2 $7 L X$

\begin{abstract}
Summary
A case is reported of dermatomyositis developing in a woman with staphylococcal osteomyelitis. After treatment for the infection, the dermatomyositis resolved and no other cause for it has been found. Dermatomyositis has not previously been described in conjuction with a staphylococcal infection.

\section{Introduction}

Polymyositis and dermatomyositis may be asscciated with autoimmune phenomena and with malignancy. The initiating factors are unclear; viral infections have been proposed (Pearson and Bohan, 1977) and a few cases have been associated with bacterial and parasitic infections (Naidoo and Chan, 1975; Kegen, Kimball and Christian, 1974; Greenlee et al., 1975; Samuels and Rietschel, 1976). Staphylococcal infection is recognized as causing pyomyositis by direct involvement of skeletal muscle, particularly in the tropics (Levin, Gardner and Waldvogel, 1971). No link has been drawn between staphylococcal infection and polymyositis or dermatomyositis. A case is reported of dermatomyositis associated with a septicaemia due to Staphylococcus aureus and osteomyelitis of the cervical spine.
\end{abstract}

\section{Case history}

A 49-year-old teacher was admitted with progressive pain and stiffness of the neck for 10 days. Four days before admission she had developed generalized stiffness of the joints and pain and weakness of the muscles. The left elbow had become red. The day before admission the legs became generally swollen, she was too weak to get out of bed without help and was breathless. Penicillin had been prescribed without effect.

Past medical history, social and family histories were not contributory. She was on no other drugs and there were no known allergies.

On examination she was unwell, flushed, dehydrated and dyspnoeic at rest, with a temperature of $37.6^{\circ} \mathrm{C}$. The limbs were swollen with slight pitting oedema but there was no facial oeden Erythematous patches were noted over the faje, neck, chest and limbs. The joints, particularly the elbows and knees, were swollen and tender ơn passive movement. There was marked generalizigd tenderness and weakness of the muscles particulappy in the proximal groups. Muscles of the neck, tongme, jaw and respiratory muscles were involved and there was dysphagia and dysarthria. The reflexis were symmetrically diminished and the plantofrs were flexor; sensation was normal. Visual fields w full and there was no diplopia nor nystagnis. Fundoscopy was normal. The pulse was 120 min and regular, BP $160 / 70 \mathrm{mmHg}$, jugular ve pressure was not elevated, and a fourth heart sofund was heard. In the chest there were crackles at borh lung bases and in the left mid zone. Abdomin rectal and pelvic examinations were normal, as we the breasts, the thyroid and the reticuloendothe system. A clinical diagnosis of dermatomyositis was made.

Investigations showed the urine to be dak, cloudy, with red cells $200 \times 10^{6} / 1$, WBC $20 \times 10^{2}$, protein + , sugar negative and granular casis; culture was sterile. $\mathrm{Hb} 11.8 \mathrm{~g} / \mathrm{dl}$, WBC $10.3 \times 10^{2} / 1$ with a neutrophil leucocytosis, ESR was $119 \mathrm{~mm} 1$ hr. Serum sodium was $130 \mathrm{mmol} / \mathrm{l}$, potassiuำ $5.62 \mathrm{mmol} / \mathrm{l}$, creatinine $90 \mu \mathrm{mol} / \mathrm{l}$, and blog sugar $3.8 \mathrm{mmol} / \mathrm{l} . \quad \mathrm{PCO}_{2}$ was $3.46 \mathrm{kPa} ; \mathrm{PO}_{2}$ w. $10.64 \mathrm{kPa}$, PEFR was reduced at $200 \mathrm{l} / \mathrm{min}$ (predicted $400-500 \mathrm{l} / \mathrm{min}$ ). Chest X-ray showed patchy shadowing in both lung bases and mid zones. ECG showed sinus tachycardia. The CPK wess 340 i.u./l (normal 25-200 i.u./l); hydroxybutyroffe dehydrogenase 440 i.u./l (normal 150-350 i.u./R). There was no urinary myoglobin. Total serufi proteins were $53 \mathrm{~g} / \mathrm{l}$, albumin $19 \mathrm{~g} / \mathrm{l}$, plasma protefin electrophoresis showed non-specific inflammatoky change, and immunoglobulins were normal. Li\&er function tests were abnormal with gamma glutam 1 transpeptidase 143 i.u./l, alanine aminotransferase 53 i.u./l, alkaline phosphatase 633 i.u./l, bilirubi $21 \mu \mathrm{mol} / \mathrm{l}$. Four successive blood cultures grew $\$$. 
aureus resistant to penicillin but sensitive to flucloxacillin and fusidic acid. Phage typing was not performed because the organism did not fall into the groups usually used for typing. Staphylococcal antibodies measured $48 \mathrm{hr}$ after admission were: anti- $\alpha$ haemolysin 16 i.u./ml (normal $\leqslant 2$ i.u./ml), anti- $\gamma$ haemolysin 32 i.u./ml (normal $\leqslant 4$ i.u./ml), anti-micrococcal nuclease $16 \mathrm{i} . \mathrm{u} . / \mathrm{ml}$ (normal up to 4 i.u./ml). Viral studies were unremarkable. Barium meal and enema were normal and ANA, antibodies to extractable RNA and rheumatoid factors were negative. DNA and complement concentrations were normal.

Muscle biopsy from the left triceps showed changes on light microscopy of a myositis. Electron microscopy showed grossly abnormal fibrils with total disorientation of $\mathrm{Z}, \mathrm{A}$ and $\mathrm{F}$ lines; myofibrils were indistinguishable. The sarcolemmal cells showed occasional myelin figures and fat globules were quite numerous. The changes were consistent with a myositis. An electromyogram performed after treatment was begun showed patchy abnormalities also consistent with a myositis.

The patient was given i.v. fluids and with rehydration the blood urea and urine microscopy returned to normal. Flucloxacillin was given i.v., and prednisolone, $60 \mathrm{mg}$ daily was started orally. Within one week the temperature was normal, the patient was able to get out of bed unaided and by 2 weeks she could walk unaided. The peak flow rate was $400 \mathrm{l} / \mathrm{min}$. The ESR was $23 \mathrm{~mm} / 1 \mathrm{hr}$, the muscle and liver enzymes were normal and the antistaphylococcal antibodies had fallen. The chest Xray changes resolved, and the antibiotics were stopped after 15 days and the steroids halved.

Two weeks later, the neck was again painful. $\mathrm{X}$-rays showed distortion of $\mathrm{C} 4,5,6$ and tomography suggested osteomyelitis. Anti-staphylococcal antibodies and the ESR were again elevated. Flucloxacillin $250 \mathrm{mg}$ orally and fusidic acid 500 $\mathrm{mg}$ thrice daily orally were given for 6 months. Steroid therapy was reduced further to $10 \mathrm{mg}$ on alternate days and stopped after 2 further weeks. At the end of 6 months she was well. The cervical $\mathrm{X}$-rays had improved, power was normal in all muscle groups, the ESR was $15 \mathrm{~mm} / 1 \mathrm{hr}$ and the anti-staphylococcal antibodies had returned to normal limits. Muscle and liver enzymes remained normal.

After more than 2 years' follow-up there is no evidence of an underlying malignancy nor an autoimmune process.

\section{Discussion}

Polymyositis is regarded as an autoimmune inflammatory disease of skeletal muscle, dermatomyositis being a similar condition with skin involve- ment (Bohan and Peter, 1975). The initiating factor may be an infection which then initiates a hypersensitivity response which becomes directed at skeletal muscle (Pearson and Bohan, 1977). In cases associated with malignancy both the myositis and malignancy may be independent effects of a single cause. Alternatively, an immune response directed against tumour cell antigens may cross-react with muscle fibres.

Viral infections have been implicated in this process, virus-like particles having been identified on electron microscopy of affected muscles taken from patients with myositis (Chou 1968; BenBassat and Machtey, 1972; Greco, Askenase and Kashgarian, 1977).

Acute myositis has been associated with influenza (Mejlszenkier et al., 1973; Barton and Chalhub, 1975; Mason and Keller, 1975; Dietzman et al., 1976) and influenza B infections (Mason and Keller, 1975). An initial direct toxic effect of the virus has been suggested and a host immune response may then develop, directed against skeletal muscle. A link with Coxsackie B infections is suggested (Travers $e t$ al., 1977) and also typhoid fever (Naidoo and Chan, 1975) and toxoplasmosis (Kegen et al., 1974; Greenlee et al., 1975; Samuels and Rietschel, 1976).

The present case seems to be the first in which staphylococci have been implicated in polymyositis although they cause pyomyositis by direct involvement of striated muscle (Levin et al., 1971).

The clinical evidence of dermatomyositis was strong with an acute onset of generalized muscle weakness, and tenderness involved particularly the proximal muscles and the neck. The rash was typical of dermatomyositis and there was evidence of joint involvement. There was no evidence of an underlying malignancy.

CPK and hydroxybutyrate phosphokinase concentrations were only mildly elevated but they may be normal in $10 \%$ of cases (Pearson and Bohan, 1977). Results of electromyographic studies performed during the recovery phase were compatible with a myositic process without evidence of a nerve conduction defect. Histology confirmed a myositis. There was no laboratory evidence of viral infection or an autoimmune process but demonstration of auto-antibodies to muscle tissue was not undertaken. Clinical and laboratory findings thus strongly support the diagnosis of dermatomyositis although without evidence of underlying malignancy or autoimmune disease. The findings of a staphylococcal septicaemia, the later discovery of osteomyelitis of the cervical spine and elevated staphylococcal antibodies were all evidence of a significant and deep-seated staphylococcal infection.

Rapid clinical improvement followed treatment 
with loss of muscle tenderness, return of muscle power and subsidence of the erythematous rash. This was accompanied by sterilization of the blood, return of the staphylococcal antibodies to normal and the later healing of the cervical osteomyelitis.

Cases of acute post viral myositis seem to be self limiting (Mejlszenkier et al., 1973; Barton and Chalhub, 1975; Mason and Keller, 1975; Dietzman et al., 1976) and treatment of the infection in typhoid and toxoplasma polymyositis seems to improve the muscle weakness.

The association of dermatomyositis and staphylococcal infection in this patient raises the possibility (although this is difficult to prove conclusively) that the latter was the cause of the former. Response to anti-staphylococcal treatment alone would have been helpful in this respect but this was not thought to be justifiable. However, there was no relapse as the steroids were withdrawn.

\section{References}

Barton, L.L. \& Chalhub, E.G. (1975) Myositis associated with influenza A infection. Journal of Pediatrics, 87, 1003.

Ben-Bassat, M. \& Machtey, I. (1972) Picornavirus-like structures in acute dermatomyositis. American Journal of Clinical Pathology, 58, 245.

Bohan, A. \& Peter, J.B. (1975) Polymyositis and dermatomyositis. New England Journal of Medicine, 292, 344, 403.

CHOU, S.M. (1968) Myxovirus-like structures and accompanying nuclear changes in chronic polymyosit
Archives of Pathology, 86, 649 .

Dietzman, D.E., Schaller, J.G., Ray, C.G. \& Reed, M.E.(1976) Acute myositis associated with influenza $B$ infectio Pediatrics, 57, 255.

Greco, T.P., Askenase, P.W. \& Kashgarian, M. (197z Postviral myositis: myxovirus-like structures in affecte muscle. Annals of Internal Medicine, 86, 193.

Greenlee, J.E., Johnson, W.D., CamPa, J.F., Adelma市 L.S. \& SANDE, M.A. (1975) Adult toxoplasmosis pre senting as polymyositis and cerebellar ataxia. Annals of Internal Medicine, 82, 367.

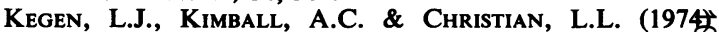
Serological evidence of toxoplasmosis among patients with polymyositis. American Journal of Medicine, 56, 186.

LEVIN, M.J., GARDNER, P. \& WaldVOGEL, F.A. (197f్ 'Tropical pyomyositis'. An unusual infection due Staphylococcus aureus. New England Journal of Medicine 284, 196.

Mason, W. \& Keller, E. (1975) Acute transient myositis with influenza-like illness. Journal of Pediatrics, 86, 813.

Mejlszenkier, J.D., Safran, A.P., Healy, J.J., Embree, K. \& OuelletTE, E.M. (1973) The myositis of influenzt. Archives of Neurology, 29, 441.

NaIDoo, P.M. \& Chan YaN, C. (1975) Typhoid polymy sitis. South African Medical Journal, 49, 1975.

Pearson, C.M. \& Bohan, A.B. (1977) The spectrum polymyositis and dermatomyositis. Medical Clinics of North America, 61, 439.

SAMUels, B.S. \& RiETSChel, R.L. (1976) Polymyositis an toxoplasmosis. Journal of the American Medical Association 235, 60.

Travers, R.L., Hughes, G.R.V., Cambridge, G. \& Sewele J.R. (1977) Coxsackie B neutralisation titres in myositis/dermatomyositis. Lancet, i, 1268. 